\title{
PATIENT-DIRECTED GAZE AS A TOOL FOR DISCOVERING AND HANDLING PSYCHOSOCIAL PROBLEMS IN GENERAL PRACTICE
}

\author{
Jozien M. Bensing, Jan J. Kerssens, and Marja van der Pasch
}

\begin{abstract}
In this study, one particular form of nonverbal behavior-patient-directed gaze-was examined in relation to the general practitioner's performance in psychosocial care. Data were available from a random sample of 337 videotaped consultations and accompanying questionnaires from both general practitioner and patient. The relevance of general practitioners' gaze in psychosocial care was demonstrated in several ways: (1) general practitioners' gaze was associated with affective verbal behavior and with instrumental behavior on psychosocial topics; (2) general practitioners' gaze was related to patients' share of talking and the number of health problems presented, especially as regards psychological and social health problems; (3) in consultations with a relatively high degree of patient-directed gaze, general practitioners were found to be more aware of patients' psychosocial history and were better at identifying patients suffering mental distress. Patient-directed gaze appears to be a useful technique, both for decoding people's mental problems and for showing interest in the patient's story. This may encourage the patient to talk about worries that would otherwise remain concealed. In medical education, nonverbal techniques should be taught as distinct from verbal communication strategies.
\end{abstract}

Discovering the true nature of the patient's health problem and translating it into a correct diagnosis are the first and perhaps most important tasks for the general practitioner. These tasks depend in part on the exchange of verbal information (i.e., information seeking and providing information) between general practitioner and patient (Hall, Roter, \& Katz, 1988; Inui \& Carter, 1985; Tuckett \& Williams, 1985; Waitzkin, 1985; Waitzkin \& Brit, 1988). However, there is a growing awareness of the importance of nonverbal behavior in the diagnostic process (Bensing, 1991a; Cassell, 1991;

Thanks are extended to Glynn Coates, John F. Dovidio, and Robin DiMatteo for their comments as reviewers on the manuscript.

Address correspondence to Jozien M. Bensing, Ph.D., Netherlands Institute of Primary Health Care (NIVEL), P.O. Box 1568, 3500 BN, Utrecht, the Netherlands. 
JOURNAL OF NONVERBAL BEHAVIOR

Roter \& Hall, 1992). Because most of the literature about the relevance of communication in the diagnostic process is about verbal behavior, rather than about nonverbal behavior, this study was designed to explore the relationship of-one form of nonverbal behavior-patient-directed gaze-to a particularly difficult part of the diagnostic process, general practitioners' awareness of patients' psychosocial problems and mental health status.

The Relevance of Nonverbal Behavior in the Psychodiagnostic Process: A Review of the Literature

Many patients go to their general practitioner with health problems that cannot be fully understood on the basis of a biomedical model (Bensing, 1991a; Cassell, 1991; Pendleton \& Bochner, 1983; White, 1988). Psychological and social factors influence the onset, course, and outcome of many diseases (Maes, Spielberger, Defares, \& Sarason, 1988; White, 1988). General practitioners have to be aware of these factors in order to provide the care that is needed by their patients. The biomedical model should therefore be extended to include a "biopsychosocial model" (Engel, 1977), in which biological theories about the etiology of health problems are supplemented by psychological theories about health and health care. Relevant contributions can be expected from social psychology, because healing can be seen as a process that is partially interpersonal (Friedman, 1979), and from clinical psychology, because psychotherapeutic theories can provide the general practitioner with guidelines for behaviors that facilitate patients talking about psychosocial topics (Bensing, 1991b). Both disciplines point to doctor-patient communication as an important tool in medicine. To quote Carole Guzman, chairman of the Canadian Medical Association, "Medicine is a delicate balance of art, science and communication" (Gezondheidsraad, 1991, p. 4).

Patients are very subtle in their communication about distress (DiMatteo, Taranta, \& Friedman, 1980). They usually do not need much encouragement to talk about somatic problems but are often reluctant to talk about nonmedical matters, either because they expect the doctor not to be interested in these matters, because of embarrassment and the fear of appearing foolish, or because of real anxiety about the possible significance of the symptoms (Roter \& Hall, 1992). Even patients with serious psychological distress only present somatic problems during the consultation (Katon, Korff, \& von Lin, 1990; Vasquez-Barquero, Diez Manrique, \& Gaite, 1992; Verhaak \& Tijhuis, 1994). As a consequence, general practitioners 
often do not recognize the patient's psychosocial problems (Goldberg \& Bridges, 1987; Ormel, van den Brink, \& Koeter, 1990; Skuse \& Williams, 1984). This may lead to patient dissatisfaction, noncompliance, and even worsening health (Cassell, 1991; Roter \& Hall, 1992; White, 1988). Consequently the general practitioner needs a high degree of sensitivity to the patient's psychosocial problems and good communication skills to deal with these problems.

In psychotherapeutic theories the core concept of "empathy" refers to the therapist's sensitivity to the patient's needs (Rogers, 1951). Empathy can be defined as the physician's ability to show the patient that she or he really understands the patient's problems (Hornsby \& Franklin, 1979). Empathy is argued to be a necessary condition in making patients feel safe enough to speak up about the things they are really worried about (Carkhuff, 1969; Truax, 1971). Empathy can be expressed verbally (by paraphrases, reflections, open questions, verbal encouragements) or in nonverbal ways (especially by gaze, body positioning, and facial cues). For genuine empathy there needs to be a congruence between verbal and nonverbal behavior. Most authors agree that nonverbal behavior is an essential, perhaps the most important, mode of conveying empathy (Bensing \& Dronkers, 1992; DiMatteo \& DiNicola, 1982; Friedman, 1979; Roter \& Hall, 1992). Nonverbal behavior is relevant not only for showing interest in the other person, but also for decoding the other person's messages. DiMatteo et al. (1980) have shown that nonverbal behavior "leaks out" messages that are not meant to be conveyed. This is particularly important in communication about difficult or emotion-laden topics, such as discussing psychosocial problems in the medical setting.

Gaze takes a special place in nonverbal communication. In Western cultures, gaze is a positive value in the communication between people: listeners are expected to look at the speaker, and speakers occasionally look at the listener to check whether the information is being understood (Collier, 1985). So, looking at the patient can provide the general practitioner with more insight about the patient's emotional feelings, worries, and distress than the health problems that are presented verbally. From this it can be postulated that in the diagnostic process of psychosomatic and mental health problems more is needed than exchanges of verbal information. Emitting and receiving nonverbal information seem necessary, if the psychosocial context of the patient's health problems is to be included in the diagnostic process (Hall, Roter, \& Rand, 1981), and is even seen as an important part of psychodiagnosis (Fridlund, Ekman, \& Oster, 1985; Marks, Goldberg, \& Hillier, 1979; Verhaak, 1988). From several studies Goldberg 
JOURNAL OF NONVERBAL BEHAVIOR

\& Huxley (1992) conclude that general practitioners who are able identifiers of emotional illness have more eye contact throughout the consultation.

The Relevance of Patient-Directed Gaze in the Psychodiagnostic Process: Previous Results

Summarizing the literature we may conclude that, because patients always start with a medical problem, and are often reluctant to discuss non-medical matters, the psychodiagnostic process takes time and a relaxed, encouraging attitude from the general practitioner. Both verbal and nonverbal communication skills are prerequisites to uncover mental health problems, and proper nonverbal behavior is characterized by a high amount of patient-directed gaze.

These findings from the literature correspond with previous research of our own. In a study of 273 random videotaped general practitioner-consultations, it was demonstrated that short consultations were characterized by patients presenting only one, somatic health problem. In most of the longer consultations more than one health problem was presented, and in twothirds of the cases psychosocial problems were also presented (Bensing, 1991 a). Verhaak (1988) showed in a large observational study $(N=1524)$ that general practitioners tend to display more patient-directed gaze when discussing psychosocial topics as compared to somatic topics. He also showed the relevance of gaze as a facilitator for the discussion of psychosocial topics by analyzing consultations in which the general practitioner had assessed the patients' health problems as (partly) psychosocial in nature. In all these consultations the patients started with somatic health problems. However, there was a significant difference in the degree of gaze between consultations in which psychosocial topics were discussed in the second stage of the consultation and consultations in which the discussion was restricted to somatic topics (Verhaak, 1988). The relevance of gaze for the quality of psychosocial care was demonstrated in yet another study of 103 videotaped general practitioner-consultations with hypertensive patients. In this study there was a high correlation between the proportion of gaze and the quality of psychosocial care, as assessed by 12 independent, experienced general practitioners who were not aware of the purpose of the study (Bensing, 1991a). In this study, the proportion of gaze was the strongest discriminating factor between consultations with high versus low psychosocial quality assessments (i.e., stronger than verbal forms of affective behavior), and between consultations with high and low satisfaction on the part of patients (Bensing, 1991b). 
JOZIEN M. BENSING, JAN J. KERSSENS, MARJA VAN DER PASCH

To summarize again, from these results, it may be concluded that the discussion of psychosocial topics in the medical consultation needs time and an encouraging general practitioner attitude expressed by a high degree of gaze. Gaze was also strongly related to panel-assessed quality of psychosocial care. However, these studies shared one important disadvantage: nothing was known about patients' actual mental health status, and accordingly nothing could be said about the general practitioner's ability to detect psychological problems, nor about relevant behaviors in the psychodiagnostic process. We decided therefore to design a new study in which doctor-patient communication could be linked to patients' actual mental health status. The rationale behind this argument is that patients will always, that is, regardless of their mental health status, start the medical consultation with the presentation of somatic health problems, so that a special effort is needed from the general practitioner to detect the presence of psychosocial problems. To establish the general practitioner's ability to detect psychosocial problems and to identify relevant behaviors in this psychodiagnostic process, it is therefore necessary to know patients' actual mental health status.

\section{Research Questions}

In this article the relevance of patient-directed eye gaze to the psychodiagnostic process was studied. The general assumption was that gaze serves to facilitate the introduction and discussion of psychosocial topics in the consultation. This enables the general practitioner to detect psychologi$\mathrm{cal}$ morbidity in the patient. The following hypotheses were tested:

1. There is a positive relationship between the general practitioner's patient-directed gaze and the consultation length. This hypothesis is based on the assumption that patients usually start by presenting somatic health problems; thus, facilitating discussion about psychosocial topics will lead to longer consultations.

2. There is a positive relationship between the general practitioner's patient-directed gaze and his/her affective verbal behavior. This hypothesis is based on the assumption that there should be a congruence between verbal and nonverbal behavior in order to create "genuineness," an important part of the empathy concept.

3. There is a positive relationship between the general practitioner's patient-directed gaze and the general practitioner's instrumental behavior on psychosocial topics, but not between the general practitioner's gaze and the general practitioner's instrumental behavior on somatic 
topics. This hypothesis is based on the assumption that gaze is not necessary to encourage patients to speak about somatic problems.

4. There is a positive relationship between the general practitioner's patient-directed gaze and the quantity and quality of the patient's verbal behavior, as well as the number and nature of problems presented. This hypothesis is based on the assumption that the general practitioner's gaze will encourage the patient to talk about problems, in particular psychosocial problems.

5. There is a positive relationship between the general practitioner's gaze and the quality of the psychodiagnostic process, such as the general practitioner's awareness of the patient's psychosocial history, assessment of the patient's presenting health problems, discussion of psychosocial topics during the consultation, and-most importantthe general practitioner's correct identification of the patient's mental health status. This hypothesis is based on the assumption that patientdirected gaze is an important facilitator in the psychodiagnostic process.

6. There is a positive relationship between the general practitioner's gaze and patient satisfaction. This hypothesis is based on the assumption that patients with a worsened mental health status like to talk with their general practitioner about their psychological problems, because they need to feel known and understood (Engel, 1977).

\section{Method}

Data came from the Dutch National Study of Morbidity and Interventions in General Practice, a large nationwide study among 161 general practitioners and 340,000 patients (Bensing, de Bakker, \& van den BrinkMuinen, 1993; Foets \& Stockx, 1991). A sample of 15 general practitioners was drawn from this large study to investigate the prognosis of patients with mental health problems during one year. Our particular study consists of these general practitioners (but not of these patients). From each general practitioner a random sample of videotapes was collected on two subsequent days. We obtained a total of 337 consultations. The videocamera was positioned to show the general practitioner's full face; the patients were only seen from behind or from the side. This was partly done for reasons of unobtrusiveness (the general practitioners were rapidly accustomed to the use of video in the consultation room; we expected the patients to be more sensitive to camera influence), but mainly because we 
JOZIEN M. BENSING, JAN \}. KERSSENS, MARJA VAN DER PASCH

were interested in the general practitioner's behavior. We do not have data on patient gaze. General practitioner and patient both completed a short questionnaire for each videotaped consultation. Henceforth the term "gaze" 'will be used to refer to patient-directed gaze by the general practitioner.

Gaze was defined as the time the general practitioner looked directly into the patient's face. Gaze was measured by stopwatch and registered in seconds. Observations were made by two social scientists. The interjudge reliability for gaze was .97 (Pearson correlation). In the analyses the total amount of gaze was used as well as the proportion of gaze relative to consultation length. The reason for this is that the literature showed that a positive relationship between gaze and consultation length could be expected. However, there was no empirical evidence of how causality ran. One could argue that in longer consultations general practitioners have more opportunities to gaze, just because the consultation lasts longer. Using that line of reasoning one should only record the proportion of gaze. A more theoretically based line of reasoning, however, is that gaze encourages the patient to speak more freely during the consultation, with longer consultation length as a consequence. Accordingly one should use the absolute measure to avoid the (real) effect of gaze being masked by using a relative measure. As consultation length shows considerable variance (Dutch general practitioner-consultations lasting between 3 and $30 \mathrm{~min}$ utes), it is likely that general practitioners influence consultation length by their verbal and nonverbal behavior. Which line of reasoning has to be favored is difficult to tell. For this reason, absolute as well as relative figures are presented in this paper. In calculating the relative figures (proportion of general practitioner gaze), length of physical examination was excluded from the total consultation time.

The verbal behavior of both general practitioner and patient was measured by RIAS: Roter's Interaction Analysis System (Roter, 1989). Reliability figures varied between .63 and .98 . Affective behavior was based on social behavior (e.g., jokes, greetings), medical concern (e.g., worries, reassurances), and empathic behavior (e.g., paraphrases, reflections, showing agreement, showing partnership) (Bensing \& Dronkers, 1992). Instrumental behavior was categorized according to type of behavior (questioning, information-giving, counseling) and content (somatic and psychosocial). Mutual tuning was categorized in seeking agreement (RIAS-categories asks for understanding, bids for clarification, and asks for opinion) and disagreements (one item).

Background information was provided by both general practitioner and patient. The general practitioners answered a questionnaire about type 
and nature of the patient's health problems and their knowledge about the patient's history of psychosocial problems. Patients' health problems were coded using the International Classification of Primary Care (ICPC) (Lamberts \& Wood, 1987). In this classification system, separate "Chapters" are devoted to psychological and social problems, respectively. The general practitioner's assessment of the patients' presenting health problems was measured on a 5 point-scale, ranging from 1 (purely somatic) to 5 (purely psychosocial). The patient's psychological distress was measured by the General Health Questionnaire (GHQ), a widely used psychiatric screening instrument, to be completed by the patients themselves (Goldberg \& Bridges, 1987; Ormel et al., 1990; Wright \& Perini, 1987). The GHQ-12 was used, where scores (ranging from 0 to 12) of two and higher are considered to indicate possible psychological distress (Goldberg 1972). Correct identification of the patient's psychological distress was coded when health problems of patients with GHQ scores of two and higher were assessed by the general practitioner as "not strictly biomedical." Patient satisfaction was measured on two items: satisfaction with the time allotted and satisfaction with the interest shown by the general practitioner.

\section{Statistical Analysis}

The clustering of consultations among general practitioners is our major statistical concern. One might argue that consultations of one general practitioner would be, on the average, more alike than consultations of different general practitioners, implying that the 337 videotaped consultations cannot a priori be considered as completely independent observations. The amount of clustering can be calculated by means of the intra-class correlation coefficient $(\rho)$, which reflects the proportion of total variance of an observation that is associated with the class (in our case the general practitioner) to which it belongs (Snedecor \& Cochran, 1980). Consider the 15 general practitioners as random effects in a one-way ANOVA. Then the between variance $\left(\sigma^{2} \mathrm{GP}\right)$ is indicating the variation between general practitioners, while the pooled within variance $\left(\sigma^{2}\right)$ relates to the variation of consultations within general practitioners. $\rho$ is defined as $\sigma_{C P}^{2} /\left(\sigma^{2}+\right.$ $\sigma^{2} \mathrm{GP}$ ). When $\sigma_{\mathrm{GP}}^{2}$ is close to zero, $\rho$ is also close to zero. In that case there is no cluster effect and the consultations can be considered as 337 independent observations. On the other hand, when $\sigma^{2}$ is close to zero, $\rho$ is close to unity. In that case there is no variation within general practitioners, the cluster effect is complete, and we have only 15 independent observations. Table 1 presents intra-class correlation coefficients for various general practitioner behaviors. 
JOZIEN M. BENSING, JAN I. KERSSENS, MARJA VAN DER PASCH

TABLE 1

Intra-class Correlation Coefficients for Various GP Behaviors, Measured on the Level of Consultations

\begin{tabular}{ll}
\hline GP behavior & Intra-class $\mathrm{r}$ \\
\hline Total gaze & $0.08^{* * *}$ \\
Length of consultation & $0.07^{* *}$ \\
GPs' verbal affective behavior & $0.18^{* * *}$ \\
Social behavior & 0.04 \\
Medical concern & $0.10^{* * *}$ \\
Empathic behavior & $0.16^{* * *}$ \\
GPs' instrumental behavior & \\
Somatic & $0.18^{* * *}$ \\
Questioning & $0.08^{* * *}$ \\
Information giving & $0.14^{* * *}$ \\
Counseling & $0.12^{* * *}$ \\
Psychosocial & $0.09^{* * *}$ \\
Questioning & $0.14^{* * *}$ \\
Information giving & 0.00 \\
Counseling & 0.03 \\
GPs' tuning to the patient & \\
Seeking agreement & $0.20^{* * *}$ \\
Disagreement & 0.02 \\
\hline Note. GP = general practitioner. The number of GPs is 15 and the number of consultations \\
is 337. $<$ *01, *** $p<.001$ & \\
\hline
\end{tabular}

Note that none of the coefficients is close to unity. The highest coefficients are those of the general practitioner seeking agreement with the patient, the sum of the general practitioners' affective verbal components, and the sum of the general practitioner's somatic instrumental behavior components. The coefficient for the variable of main interest-total gazewas found to be .08 which is considered moderate to low (Goldstein, 1987). The value of .08 indicates that $8 \%$ of the variance is between general practitioners, while the remaining $92 \%$ is due to the pooled within variance. One might tentatively say that, instead of 337 independent observations, we have approximately $307(.92 \times 337)$ independent observations. So we conclude that the consultations within one general practi- 
JOURNAL OF NONVERBAL BEHAVIOR

tioner have indeed a greater degree of similarity than consultations of different general practitioners, but only slightly so.

The idea of observation dependencies is further formalized in the hierarchical linear model approach (Bryk \& Raudenbusch, 1992). This approach takes into account whatever clustering the data present and adjusts the standard errors of the estimated coefficients accordingly. (Recall that the statistical significance of a coefficient is determined by dividing the estimate by its standard error.) Hierarchical linear models are regression models. For ease of interpretation all variables were transformed to $z$ scores, so regression coefficients become correlation coefficients (Kerlinger \& Pedhazur, 1973, p. 26). Following standardization a series of models was computed with each behavioral component (see Tables 2-4) as an explanatory variable and the total amount of gaze as a response variable. This was repeated in another series with the relative amount of gaze as the response variable. Hierarchical linear models specified in this way are named "one-way ANCOVA with random effects" models (Bryk \& Raudenbusch, 1992, p. 18).

We have used the ML3 software (Prosser, Rashbash, \& Goldstein, 1991) to analyze all our data.

\section{Results}

As was expected, there was a positive relationship between gaze and consultation length $(r=.71, p<.001)$. For reasons explained above, the results are presented for both the total amount of gaze as well as the proportion of gaze.

Table 2 shows the relationship between general practitioner gaze and general practitioner verbal behavior. The total amount of gaze is related positively to all categories of general practitioner verbal behavior, with higher correlations for general practitioner empathic behavior and general practitioner instrumental behavior on psychosocial topics than for general practitioner social behavior, medical concern, and general practitioner instrumental behavior on somatic topics. Gaze is also more closely related to general practitioners' seeking agreement with the patient than to general practitioners' disagreements with the patients. The relative gaze (proportion) has a positive relationship with general practitioners' verbal empathy and medical concern, but not with their social behavior. It also has a positive relationship to instrumental behavior on psychosocial topics, but not the three components of instrumental behavior on somatic topics. The relative amount of gaze is significantly related to the general practitioner's 
JOZIEN M. BENSING, JAN J. KERSSENS, MARJA VAN DER PASCH

TABLÈ 2

Correlation Coefficients of Various GP Behavioral Measures with Total
Gaze and with the Proportion of Gaze Relative to Consultation Length

\begin{tabular}{llc}
\hline & \multicolumn{2}{c}{ Gaze } \\
\cline { 2 - 3 } & Total & Proportional \\
GP behavior & $r$ & $r$ \\
\hline GPs' verbal affective behavior & $0.70^{* * *}$ & $0.40^{* * *}$ \\
Social behavior & $0.22^{* * *}$ & 0.07 \\
Medical concern & $0.22^{* * *}$ & $0.17^{* *}$ \\
Empathic behavior & $0.69^{* * *}$ & $0.39^{* * *}$ \\
GPs' instrumental behavior & & \\
Somatic & $0.29^{* * *}$ & $0.14^{*}$ \\
Questioning & $0.15^{* * *}$ & 0.10 \\
Information giving & $0.25^{* * *}$ & 0.08 \\
Counseling & $0.22^{* * *}$ & 0.11 \\
Psychosocial & $0.53^{* * *}$ & $0.30^{* * *}$ \\
Questioning & $0.48^{* * *}$ & $0.25^{* * *}$ \\
Information giving & $0.29^{* * *}$ & $0.16^{* * *}$ \\
Counseling & $0.41^{* * *}$ & $0.26^{* * *}$ \\
GPs' tuning to the patient & & \\
Seeking agreement & $0.36^{* * *}$ & $0.13^{*}$ \\
Disagreement & $0.15^{* * *}$ & 0.08 \\
\hline
\end{tabular}

Note. GP = general practitioner. Correlation coefficients are computed in hierarchical linear models (337 consultations nested within $15 \mathrm{GPs}$ ).

${ }^{*} p<.05,{ }^{* *} p<.01,{ }^{* * *} p<.001$

seeking mutual agreement, but not with the general practitioner's disagreements with the patients. The pattern of correlations of the various general practitioner behavioral measures with total gaze is the same as the pattern with the proportion of gaze, but the total gaze correlations are without exception higher than the proportional gaze correlations.

The same type of pattern is shown in Table 3, where the general practitioner's gaze is related to the patient's verbal behavior. Gaze is positively related to the amount of talking the patient does (in absolute terms, as well as relative to general practitioners' speaking-time). In consultations with high gaze, more health problems are presented by the patient. Figure 1 shows that the higher number of health problems can be attributed com- 
JOURNAL OF NONVERBAL BEHAVIOR

TABLE 3

\section{Correlation Coefficients of Various Patient Behavioral Measures with Total Gaze and with the Proportion of Gaze Relative to Consultation Length}

\begin{tabular}{|c|c|c|}
\hline \multirow[b]{2}{*}{ Patient behavior } & \multicolumn{2}{|c|}{ Gaze } \\
\hline & $\begin{array}{c}\text { Total } \\
r\end{array}$ & $\begin{array}{c}\text { Proportional } \\
r\end{array}$ \\
\hline \multicolumn{3}{|l|}{ Patient talking } \\
\hline Absolute & $0.66^{* * *}$ & $0.32^{* * * *}$ \\
\hline Relative to GP & $0.31^{* * *}$ & $0.14^{*}$ \\
\hline Numbers of health problems & $0.29 * * *$ & $0.18^{* * *}$ \\
\hline \multicolumn{3}{|l|}{ Patient affective behavior } \\
\hline Social behavior & $0.17^{* * *}$ & 0.01 \\
\hline Medical concern & $0.48^{* * *}$ & $0.28^{* * *}$ \\
\hline Empathic behavior & $0.58^{* * *}$ & $0.26^{* * *}$ \\
\hline \multicolumn{3}{|l|}{ Patients instrumental behavior } \\
\hline \multicolumn{3}{|l|}{ Somatic } \\
\hline Questioning & $0.25^{* * *}$ & 0.10 \\
\hline Information giving & $0.33^{* * *}$ & $0.14^{* *}$ \\
\hline \multicolumn{3}{|l|}{ Psychosocial } \\
\hline Questioning & $0.18^{* * *}$ & $0.12^{*}$ \\
\hline Information giving & $0.54^{* * *}$ & $0.31^{* * *}$ \\
\hline \multicolumn{3}{|l|}{ Patient tuning to the GP } \\
\hline Seeking agreement & $0.40^{* * *}$ & $0.16^{* *}$ \\
\hline Disagreement & $0.23^{* * *}$ & 0.09 \\
\hline
\end{tabular}

Note. GP = general practitioner. Correlation coefficients are computed in hierarchical linear models (337 consultations nested within 15 GPs).

${ }^{*} p<.05,{ }^{* *} p<.01,{ }^{* * *} p<.001$

pletely to the greater number of psychological and social problems (Chapters $\mathrm{P}$ and $\mathrm{Z}$ of the ICPC). The total amount of general practitioner gaze is positively related to all patients' verbal behaviors especially with patients' empathic behavior $(r=.58, p<.001)$ and patients' information giving on psychosocial topics $(r=.54, p<.001)$. The relative amount of gaze is also positively related to the patients' verbal behavior, especially the patients' affective verbal behavior (with the exclusion of social behavior) and information giving (especially on psychosocial topics). The relative amount 
JOZIEN M. BENSING, JAN J. KERSSENS, MARJA VAN DER PASCH

TABLE 4

\section{Correlation Coefficients of Various GP Performance Measures and Patient Satisfaction with Total Gaze and with the Proportion of Gaze Relative to Consultation Length}

\begin{tabular}{lll}
\hline & \multicolumn{2}{c}{ Gaze } \\
\cline { 2 - 3 } Measure & Total & $\begin{array}{c}\text { Proportional } \\
\text { GPs' performance in psychosocial care }\end{array}$ \\
GPs' awareness of patients' psychosocial history & $0.19^{* * *}$ & $0.15^{*}$ \\
GPs' assessments of patients' presenting & & \\
$\quad$ health problems & $0.41^{* * *}$ & $0.32^{* * *}$ \\
Patient's GHQ score & $0.13^{* *}$ & 0.09 \\
GPs' recognition of patient's GHQ score & $0.22^{* * *}$ & $0.19^{* *}$ \\
Patient satisfaction & & \\
With time allotted & $0.18^{* * *}$ & 0.10 \\
With interest shown & $0.16^{* *}$ & $0.17^{* *}$ \\
\hline
\end{tabular}

Note. GP = general practitioner. Correlation coefficients are computed in hierarchical linear models ( 337 consultations nested within $15 \mathrm{GPs}$ ).

${ }^{*} p<.05,{ }^{* *} p<.01,{ }^{* * *} p<.001$

of gaze is also related to the patient's seeking mutual agreement, and not to his/her disagreements with the general practitioner. Again, all the total gaze correlations are higher than the proportional gaze correlations.

In Table 4 data about general practitioner's performance in psychosocial care are summarized. The total and relative amount of gaze show the same pattern. Table 4 shows that gaze is more prominent in consultations with patients whom the general practitioner knows to have had psychosocial problems in the past. General practitioner awareness of the psychosocial context of the patient's health problems is shown by the significant correlation between gaze and the number of health problems that are assessed as (partly) psychosocial in nature. There is no significant correlation between proportion of general practitioner gaze and the patient's score on the General Health Questionnaire, indicating that GHQ-caseness as such is not directly related to this measure of general practitioner gaze. There was, however, a significant correlation between total gaze and the patient's $\mathrm{GHQ}$ score. There is also a significant correlation between the general practitioner's gaze and his/her recognition of the patient's high GHQ score. 

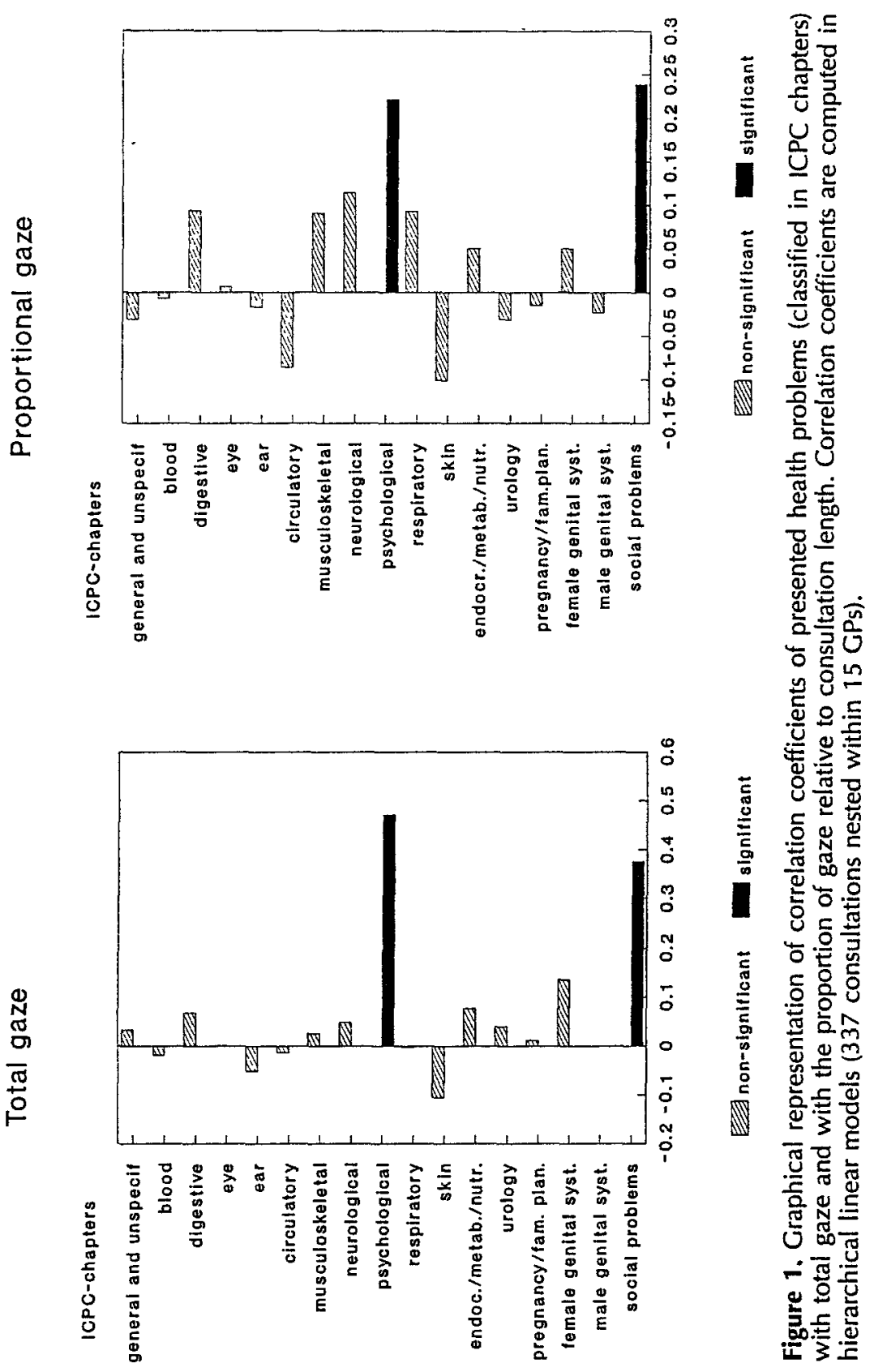
JOZIEN M. BENSING, JAN J. KERSSENS, MARJA VAN DER PASCH

In consultations with a lot of absolute and/or relative general practitioner gaze, patients are a little more satisfied with the time allotted and the interest shown by the general practitioner. In all tables, the total gaze correlations are higher than the proportional gaze correlations, with only one out of 32 exceptions (patient satisfaction with interest shown).

\section{Discussion}

The results of this study underline the important role of patient-directed gaze in medical consultations, especially when psychosocial factors are involved in the patients' health problems. The present study showed that gaze is associated with several aspects of the psychodiagnostic process. Its main contribution compared to other literature in the field (Bensing, 1991a; DiMatteo et al., 1980, 1982, 1986; Verhaak, 1988) is in the links it has been able to demonstrate between the general practitioner's gaze and his/her correct identification of the patient's mental distress, measured by a psychiatric screening instrument (GHQ). This is an important finding, because it is known from literature that many mental health problems remain unidentified in general practice, while most of these patients neither see a psychiatrist or psychologist for their mental health problems. Identifying relevant general practitioner behaviors that are associated with a better recognition of mental health problems is therefore directly relevant to clinical practice.

Let us summarize the main results. In consultations with high gaze by the general practitioner, patients seem to feel more inclined to talk freely about their concerns: they talk more (in absolute terms, but also relative to the general practitioner's speaking time), present more health problems, especially psychological and social health problems, and give more information about psychosocial issues; the consultations last longer than when there is low general practitioner gaze. It is perhaps for this reason that, in consultations with a lot of gaze, the general practitioner is more aware of the psychosocial context of the patient's health problems, and succeeds better in identifying patients with a heightened level of mental distress.

From our results it is not clear why patient-directed gaze has a positive relationship with general practitioners' better identification of mental health problems. Roter \& Hall (1992) suggest that this may be because a patient who hesitates to talk about a problem, or who is nervous or frightened or angry, may convey these feelings in a nonverbal way, which only the doctor who is more sensitive to nonverbal signals can pick up. In this 
study it has been shown that simply looking at the patient is associated with these kinds of signals and, hence, may be a useful tool for decoding and discovering hidden mental distress. These results are consistent with Marks et al.'s (1979) observation that $40.3 \%$ of the variation in correctly identifying psychiatric disorders was accounted for by the doctor's "interest and concern" (a combined measure of verbal and nonverbal behaviors). Also Fridlund et al. (1985) have pointed to the major role of the ability to emit and decode nonverbal messages in the process of psychodiagnosis. The results of our study make it plausible that gaze is an important factor in this ability to emit and decode messages and therefore facilitates the psychodiagnostic process. As patients tend to present only their physical symptoms, the uncovering of psychosocial problems is no straightforward matter in general practice. It needs special effort and special techniques (Bensing \& Verhaak, 1994; Goldberg \& Huxley, 1992; Roter \& Hall, 1992). In medical education physicians-to-be are well trained in techniques for the exchange of verbal medical information. They are much less well trained in techniques for the exchange of nonverbal information. This lack of training in nonverbal behaviors, added to the masked way in which psychosocial problems are presented in general practice, may well be the reason why general practitioners are and can be blamed by psychiatrists for missing psychiatric diagnoses. A recommendation resulting from this study is to extend training in communication skills to include nonverbal techniques, gaze in particular. Previous research has shown that this can be done to some effect (Bensing \& Sluijs, 1985; Gask, McGrath, Goldberg, \& Millar, 1987).

The mutually reinforcing relationship of verbal and nonverbal behavior is another interesting result of this study. As was expected, the general practitioner's gaze was positively related to the general practitioner's affective behavior, especially to verbal empathic behavior such as paraphrases, reflections, and so on. Note that the general practitioner's gaze was not associated with social behavior; social chatting has no relationship whatever with the quality of psychosocial care (Bensing \& Dronkers, 1992; Roter \& Hall, 1992). There is an interesting pattern between the general practitioner's gaze and his/her instrumental communicative behavior, such as questioning, information giving, and counseling. Gaze was not related to these types of behavior when somatic topics were discussed, but it was when doctor and patient talked about psychosocial issues. In philosophical literature about the task or goal of medicine, it is often claimed that incorporating psychosocial issues in medical care should be accompanied by suitable types of communicative behaviors that are different from those used in traditional medicine, that is based on the biomedical model; non- 
JOZIEN M. BENSING, JAN J. KERSSENS, MARJA VAN DER PASCH

verbal behaviors are explicitly mentioned in this literature (Cassell, 1991; Engel, 1977; Friedman, 1979; White, 1988). Our study gives some support to this claim, and forms an extra justification for increasing the training in communication skills for general practitioners and general practice trainees (Gask et al., 1987).

Some methodological points need special mention. In the analyses, a hierarchical linear model formalized the alleged dependencies in the observation caused by the nesting of consultations within general practitioners. This approach is also often used to explain variation in the lower level outcome measure by means of higher level explanatory variables. We did not attempt to do so. Our outcome measure (gaze) as well as our explanatory variables (e.g., the given amount of information) are all on the level of the consultations. It is very important to note that we did not study general practitioner attributes but general practitioner behavior, and general practitioner behavior is not constant across consultations. The observed intra-class correlation for giving information about somatic topics, for instance, is .14 . This means that only $14 \%$ of the variation proved to be at the general practitioner level, leaving the remaining $86 \%$ of the variation at the level of consultations. Providing information is, therefore, influenced more by the demands of the situation than by more general attributes. This is a very fortunate circumstance indeed, we would like to add, because general practitioners who always give the same amount of information regardless of the kind of health problems brought to their attention are not likely to be very sensitive doctors.

Another important methodological point has to be made about the type of relationships we did find. In interpreting the results, we must keep in mind that the study was designed to be correlational, which provides us with associations but not with causal explanations. In the Method section, we already touched on this problem by discussing the mutual relationship between gaze and consultation length. Gaze and consultation length coincide, but which is the chicken and which is the egg? Does gaze influence the course of events in the consultation, with the effect of making them longer? Or does the general practitioner have more opportunity to look at his/her patients, thus improving the gaze score? By presenting both the total and relative figures we can get some idea about the processes involved: both measures yield the same results, but the correlations are higher with the absolute measure of gaze. This means that, in longer consultations, there is more opportunity to display gaze as well as several kinds of verbal behaviors, but even when controlled for the length of the consultation, it can be argued that gaze still "does the trick" of eliciting certain kinds of behavior, affective behavior as well as instrumental behav- 
ior on psychosocial topics. So, probably both lines of reasoning are partly true, and reinforce each other in circular processes. For the same reason it cannot be concluded from this study that gaze is responsible for a better psychodiagnostic process. One could argue that, in consultations in which psychosocial issues are discussed, the general practitioner naturally has more gaze with the patient, because in these consultations the patient talks a lot, and listening is associated with more gaze than speaking, as some authors have demonstrated (Argyle, 1978). It is not unthinkable that here, too, circular processes are more probable than simple causal ones. However, the definite proof can only be arrived at in carefully designed experiments. For instance, we can instruct simulated patients to mention their psychosocial problems in different phases of the consultation and observe the subsequent amount of gaze. Or we can instruct general practitioners to make various amounts of gaze in different consultations and record the nature and number of health problems brought up as well as the length of time of the consultations. A joint effort of fundamental and applied research seems appropriate for a further tackling of this problem.

\section{References}

Argyle, M. (1978). The psychology of interpersonal behaviour, 3rd ed. Harmondsworth, Middlesex: Penguin Books Ltd.

Bensing, J. M. (1991a). Doctor-patient communication and the quality of care. An observation study into affective and instrumental behavior in general practice. Utrecht: Netherlands Institute of Primary Health Care.

Bensing, J. M. (1991b). Doctor-patient communication and the quality of care. Social Science \& Medicine, 32, 1301-1310.

Bensing, J. M., \& Dronkers, J. (1992). Instrumental and affective aspects of physician behavior, Medical Care, 30, 283-297.

Bensing, J. M., Bakker, D. de, \& Brink-Muinen, A van den. (1993). Gender differences in practice style: A Dutch study of general practice. Medical Care, 31, 219-229.

Bensing, J. M., \& Sluijs, E. M. (1985). Evaluation of an interview training course for general practitioners. Social Science \& Medicine, 20, 733-744.

Bensing, J. M., \& Verhaak, P. F. M. (1994). Psychische problemen in de huisartspraktijk veelvormiger en diffuser dan in de psychiatrie. Nederlands Tijdschrift Geneeskunde, 138, 130-135.

Bryk, A. S., \& Raudenbusch, S. W. (1992). Hierarchical linear models: Applications and data analysis methods. Newbury Park, CA: Sage.

Carkhuff, R. R. (1969). Helping and human relations: A primer for lay and professional helpers. Vol. II. Practice and research. New York: Holt, Rinehart and Winston.

Cassell, E. J. (1991). The nature of suffering and the goals of medicine. New York: Oxford University Press.

Collier, G. (1985). Emotional expressions. Hillsdale, NJ: Erlbaum.

DiMatteo, M. R., Taranta, A., Friedman, H. S., \& Prince, L. M. (1980). Predicting patient satisfaction from physicians' nonverbal communication skills. Medical Care, 18, 376-387. 
JOZIEN M. BENSING, JAN J. KERSSENS, MARJA VAN DER PASCH

DiMatteo, M. R., \& DiNicola, D. D. (1982). Achieving patient compliance. The psychology of the medical practitioner's role. New York: Pergamon.

DiMatteo, M. R., Hays, R. D., \& Prince, L. M. (1986). Relationship of physicians' nonverbal communication skill to patient satisfaction, appointment noncompliance, and physician workload. Health Psychology, 5, 581-594.

Engel, G. L. (1977). The need for a new medical model: A challenge for biomedicine. Science, 197, 129-136.

Engel, G. L. (1988). How much longer must medicine's science be bound by a seventeenth century world view? In K. L. White (Ed.), The task of medicine: Dialogue at Wickenburg. Menlo Park, CA: Henry J. Kaiser Family Foundation.

Foets, M., \& Stockx, L. J. (submitted). The Dutch National Morbidity Survey of General Practice compared with national morbidity surveys in England and Wales.

Fridlund, A. J., Ekman, P., \& Oster, H. (1987). Facial expression of emotion: A review of literature, 1970-1983. In A. Siegman \& S. Feldstein (Eds.), Nonverbal behavior and communication (pp. 143-224). Hillsdale, NJ: Erlbaum.

Friedman, H. S. (1979). Nonverbal communication between patients and medical practitioners. Journal of Social Issues, 35, 82-99.

Gask, L., McCrath, G., Goldberg, D., \& Millar, T. (1987). Improving the psychiatric skills of established general practitioners: Evaluation of group teaching. Medical Education, 21, 362-368.

Gezondheidsraad: Beraadsgroep Geneeskunde (Health Council). (1991). Medisch handelen op een tweesprong. The Hague: Gezondheidsraad.

Goldberg, D. P. (1972). The detection of psychiatric illness by questionnaire. London: Oxford University Press.

Goldberg, D. P., \& Bridges, K. (1987). Screening for psychiatric illness in general practice: The GP versus the screening questionnaire. Journal of the Royal College of General Practitioners, 37, 15-18.

Goldberg, D. P., \& Huxley, P. (1992). Common mental disorders: A biosocial model. London: Routledge.

Goldstein, H. (1987). Multilevel models in educational and social research. London: Griffin \& Co.

Hall, J. A., Roter, D. L., \& Rand, C. S. (1981). Communication of affect between patient and physician. Journal of Health and Social Behavior, 22, 18-30.

Hall, J. A., Roter, D. L., \& Katz, N. R. (1988). Meta-analysis of correlates of provider behavior in medical encounters. Medical Care, 26, 657-675.

Hornsby, J. L., \& Franklin, E. P. (1979). A model for communication skills: Development for family practice residents. Journal of Family Practice, 81-76.

Inui, T. S., \& Carter, W. B. (1985). Problems and prospects for health services research on provider-patient communication. Medical Care, 23, 521-538.

Katon, W., Korff, M. von, Lin, E., Lipscomb, P., Russo, J., Wagner, E., \& Polk, E. (1990). Distressed high utilizers of medical care. DSM-III-R diagnoses and treatment needs. General Hospital Psychiatry, 12, 355-362.

Kerlinger, F. N., \& Pedhazur, E. J. (1973). Multiple regression in behavioral research. New York: Holt, Rinehart and Winston.

Lamberts, H., \& Wood, M. (Eds.) (1987). The international classification of primary care (ICPC). Oxford: Oxford University Press.

Maes, S., Spielberger C. D., Defares, P. B., \& Sarason, I. G. (Eds.) (1988). Topics in health psychology. Chichester: John Wiley \& Sons.

Marks, J. N., Goldberg, D. P., \& Hillier, V. F. (1979). Determinants of the ability of general practitioners to detect psychiatric illness. Psychological Medicine, 9, 337-353.

Ormel, J., Brink, W. van den, Koeter, M. J. J., Giel, R., Meer, K. vander, Willige, G. van de, \& Wilmink, F. W. (1990). Recognition, management and outcome of psychological disorders in primary care: A naturalistic follow-up study. Psychological Medicine, 20, 909-923. 
JOURNAL OF NONVERBAL BEHAVIOR

Pendleton, D. A., \& Bochner, S. (Eds.) (1983). Doctor-patient communication. London: Academic Press.

Prosser, R., Rasbash, J., \& Goldstein, H. (1991). Software for three-level analysis. London: Institute of Education, University of London.

Rogers, C. R. (1951). Client centered therapy. Boston: Houghton Mifflin.

Roter, D. L. (1989). The Roter method of interaction process analysis. Baltimore: Johns Hopkins University (unpublished manual).

Roter, D. L., \& Hall, J. A. (1992). Doctors talking with patients/Patients talking with doctors: Improving communication in medical visits. Westport, CT: Auburn House.

Skuse, D., \& Williams, P. (1984), Screening for psychiatric disorder in general practice $P_{s y-}$ chological Medicine, 14, 365-377.

Snedecor, G. W., \& Cochran, W. G. (1980). Statistical methods. Ames, IA: The lowa State University Press.

Strecher, V. J. (1983). Improving physician-patient interactions: A review. Patient Counselling and Health Education, 4, 129-136.

Truax, C. B., \& Mitchell, K. M. (1971). Research on certain therapists interpersonal skills in relation to process and outcome. In A. Bergin \& S. Garfield (Eds.), Handbook of psychotherapy and behavior. (pp. 299-344). New York: John Wiley \& Sons.

Tuckett, D., \& Williams, A. (1984). Approaches to the measurement of explanation and information-giving in medical consultations: A review of empirical studies. Social Science \& Medicine, 18, 571-580.

Vasquez-Barquero, J. L., Diez Manrique, J. F., Gaite, L., Igleslias Garcia, C., Artal, J., Roberts, S. E., \& Wilkinson, G. (1992). Why people with probable minor psychiatric morbidity consult a doctor. Psychological Medicine, 22, 495-502.

Verhaak, P. F. M. (1988). Detection of psychological complaints by general practitioners. Medical Care, 26, 1009-1020.

Verhaak, P. F. M., \& Tijhuis, M. A. R. (1994). The somatizing patient in primary care, International Journal of Psychiatry in Medicine, 24, 163-183.

Waitzkin, H. (1985). Information-giving in medical care. Journal of Health and Social Behavior, 26, 81-101.

Waitzkin, K., \& Britt, T. (1989). Changing the structure of medical discourse: Implications of cross-national comparisons. Joumal of Health and Social Behavior, 30, 436-449.

White, K. L. (1988). The task of medicine: Dialogue at Wickenburg. Menlo Park, CA: The Henry Kaiser Foundation.

Wright, A. F., \& Perini, A. F. (1987). Hidden psychiatric illness: Use of the General Health Questionnaire in general practice. Journal of the Royal College of General Practitioners, $37,164-167$. 